\title{
Infant feeding practices and dietary consumption of US infants and toddlers: National Health and Nutrition Examination Survey (NHANES) 2003-2012
}

\author{
Kathleen E Davis ${ }^{1, *}$, Xilong Li ${ }^{2}$, Beverley Adams-Huet ${ }^{2}$ and Lona Sandon ${ }^{3}$ \\ ${ }^{1} T e x a s$ Woman's University, Nutrition and Food Sciences, PO Box 42588, Denton, TX 76204, USA: ${ }^{2}$ University of \\ Texas Southwestern Medical Center, Clinical Sciences, Dallas, TX, USA: ${ }^{3}$ University of Texas Southwestern Medical \\ Center, Clinical Nutrition, Dallas, TX, USA
}

Submitted 30 March 2017: Final revision received 1 September 2017: Accepted 25 September 2017: First published online 23 November 2017

\begin{abstract}
Objective: To compare infant and toddler anthropometric measurements, feeding practices and mean nutrient intakes by race/ethnicity and income.

Design: Cross-sectional analysis using general linear modelling. Ten years of survey data (2003-2012) were combined to compare anthropometric measurements, feeding practices and mean nutrient intakes from a nationally representative US sample.

Setting: The 2003-2012 National Health and Nutrition Examination Survey (NHANES).

Subjects: Infants and toddlers ( $n$ 3669) aged 0-24 months.

Results: Rates of overweight were higher among Mexican-American infants and toddlers $(P=0.002)$. There were also several differences in feeding practices among groups based on race/ethnicity. Cessation of breast-feeding occurred earlier for non-Hispanic black and Mexican-American $v$. non-Hispanic white infants $(3.6$ and $4.2 v .5 .3$ months; $P<0.0001 ; P=0.001)$. Age at first feeding of solids was earlier for white than Mexican-American infants $(5.3 v .5 .7$ months; $P=0 \cdot 02)$. There were differences in almost all feeding practices based on income, including the lowest-income infants stopped breast-feeding earlier than the highest-income infants $(3 \cdot 2 v \cdot 5 \cdot 8$ months, $P<0 \cdot 0001)$. Several differences in mean nutrient intakes by both race/ethnicity and income were also identified.

Conclusions: Our study indicates that disparities in overweight, feeding practices and mean nutrient intakes exist among infants and toddlers according to race/ ethnicity, which cannot be disentangled from income.
\end{abstract}

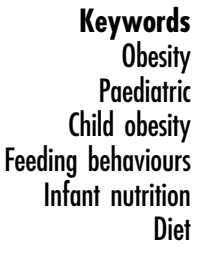

Childhood overweight and obesity are among the greatest risks to the future health of US children and adults. Early obesity increases risk for dyslipidaemia, pre-diabetes, type 2 diabetes, hypertension, asthma, non-alcoholic fatty liver disease, anxiety and depression in both children and adults $^{(1-11)}$. Consequently, preventing childhood obesity is a major national health priority ${ }^{(12)}$. While efforts to combat childhood obesity have expanded, prevalence remains $\operatorname{high}^{(13,14)}$.

Obesity is not defined in infants and toddlers, but overweight is defined as weight-for-length greater than or equal to the 95th percentile on the Centers for Disease Control and Prevention growth charts ${ }^{(15)}$. Obesity in the very next age group (2- to 5-year-olds) is defined in essentially the same way, using $\mathrm{BMI} \geq 95$ th percentile (which is also an indicator of weight-for-length). Using this indicator, the rate of overweight in infants and toddlers for 2011-2012 (8.1\%) was only slightly less than the rate of obesity in 2 - to 5 -year-olds $(8.4 \%)^{(15)}$.

Several studies indicate that rapid weight gain in infancy correlates with obesity in childhood and adulthood ${ }^{(16-22)}$. The time of onset and causes of early obesity are uncertain, but one study identified a median 'tipping point' of 22 months for the infant transition to overweight, which decreased to 15 months when adjusted for infants who were overweight by the first physician visit ${ }^{(23)}$. Crossing weight-for-length percentiles in the first 6 months of life is also associated with a significantly higher rate of obesity at age 5 years ${ }^{(24)}$. Given the potentially severe consequences of early excess weight gain, identifying feeding practices in infancy which could prevent the onset of overweight is essential. 
Infant feeding practices hypothesized to be protective against overweight include breast-feeding, delayed introduction of sugar-sweetened beverages, exposure to a wide range of textures and tastes, responsive feeding and appropriate introduction of solid foods ${ }^{(21,25-27)}$. However, there are few studies reporting anthropometric measurements and early feeding practices in children from birth to age 24 months, and they are based on samples which are less ethnically diverse and higher income than the US population ${ }^{(28-33)}$. While Mexican-American infants have higher rates of overweight compared with other groups, data on feeding practices or nutrient intakes stratified according to race/ethnicity or income have not been reported $^{(14)}$.

The National Health and Nutrition Examination Survey (NHANES) is an ongoing programme designed to assess the health and nutrition status of adults and children in the USA. It describes race/ethnicity, income, anthropometric measurements and parental feeding practices of US children, making it useful to identify differences in practices protective against, as well as those associated with, early overweight and obesity ${ }^{(34)}$. The purpose of the present study was to use data from approximately 10 years of NHANES surveys (2003-2012) to compare infant and toddler anthropometric measurements, feeding practices and mean nutrient intakes by race/ethnicity. Because there are also disparities in income by race/ethnicity in the USA, we also aimed to explore differences in these variables by income.

\section{Participants and methods}

\section{Study design}

NHANES uses a stratified, multistage probability design to provide cross-sectional health data on a nationally representative sample of all races/ethnicities in the USA. The current study included all infants and toddlers from 0 to 24 months of age in NHANES 2003 to 2012. An approximately 10-year period was chosen to achieve sufficiently large groups by race and ethnicity for comparison. While obesity rates are thought to have changed among 2- to 5-year-old children during 2003-2012, in the $0-24$ months age group, the rates were steady ${ }^{(13,14)}$; thus data from these years were combined.

The NHANES methodology is explained in detail in readily available public reports ${ }^{(35)}$. Briefly, the methodology is as follows. Respondents were interviewed in their homes and subsequently in mobile examination centres, where the examination component, including obtaining anthropometric measurements and collection of dietary intake data, took place. During a home interview, parents completed the Diet Behavior and Nutrition Questionnaire, which asks questions such as "Was the child ever breastfed or fed breastmilk?' Dietary data were obtained using the US Department of Agriculture's Automated Multiple-Pass
Method with parents acting as proxy reporters. The Automated Multiple-Pass Method is a validated $24 \mathrm{~h}$ recall method. Participants self-classified their income into categories at \$US 5000 intervals from \$US 0 to \$US 24999 and at intervals of \$US 10000 or more at \$US 25000 to \$US 74999 annually. Parents self-classified their race/ethnicity as Mexican-American, non-Hispanic white, non-Hispanic black, other Hispanic, and other race. Anthropometric measurements included reported birth weight, measured weight and measured length.

\section{Data analysis}

Participants were categorized as $\geq 95$ th percentile (overweight) or $<95$ th percentile for weight-for-length according to the WHO chart. The WHO charts were chosen because, compared with the Centers for Disease Control and Prevention growth charts, they are more representative of how diverse, breast-fed infants and toddlers grow under optimal conditions ${ }^{(36)}$.

Because we sought to compare only nutrient intakes from foods and beverages by race/ethnicity and income without comparing mean intakes with intake standards such as the Dietary Reference Intakes, nutrient intake data presented are based on food and beverage intakes from the first day's recall. This does not include supplement intake, nor does it use statistical methods to estimate usual intakes. NHANES includes data on breast-feeding but does not estimate intakes of nutrients from breast milk; thus for infants whose caregivers reported breast-feeding, the methods of Butte et al. and Briefel et al. were used to estimate breast-milk intake ${ }^{(37,38)}$ (see online supplementary material, Supplemental Table 1). Nutrient intakes from breast milk were estimated using the Nutrition Data System for Research (NDSR) 2015 dietary analysis program (Nutrition Coordinating Center, University of Minnesota, Minneapolis, MN, USA).

Family annual income was minimally stratified. The lower income categories were combined into two groups of approximately \$US 10000 intervals. One lower-middle income group of \$US 20000-34999 annually was formed, as well as two middle income and two upper-middle income categories of approximate \$US 10000 intervals. The upper income ( $>$ WS 75000) category was left unchanged.

For all analyses, the appropriate complex survey design sample weights were taken into account because of the unequal probabilities for selection as described on the NHANES website. Responses to questions which the participant refused to answer or answered 'don't know' were treated as missing. If a participant had missing data for a particular outcome, the participant was not included in the analysis of that outcome.

The descriptive analyses are reported as survey-weighted mean and $95 \%$ confidence level (CL) for continuous variables, or frequency and percentage for categorical 
variables. The differences in anthropometric measurements and infant feeding practices among race/ethnicities and income levels and interactions were tested in surveyweighted general linear models. Statistical analysis was conducted using the statistical software package SAS version $9 \cdot 4$. A $P$ value of $<0.05$ was considered statistically significant.

\section{Results}

Data were extracted for 3840 infants and toddlers from 2003 to 2012. Dietary intake data were missing for 171 participants, resulting in $n 3669$ for dietary analysis. Missing data points were few for variables such as reported birth weight ( $n$ 16), weight ( $n$ 15) and length ( $n$ 10), resulting in $n 3628$ for the variable weight-for-length $\geq 95$ th percentile or $<95$ th percentile. There were similar numbers of males and females (51\% male and $49 \%$ female). Due to intentional oversampling in the recent NHANES surveys, there were large numbers of MexicanAmerican (33\%) and non-Hispanic black (20\%) participants. There were equal proportions of infants in the age groups 0-5.9 months and 6-11.9 months (30 and 29\%, respectively) and $41 \%$ in the $12-24$ months group. Most participants were low income (<\$S 35 000; $56 \%$; Table 1).

Mexican-American and non-Hispanic black infants weighed less at birth than non-Hispanic white infants ( $P<0.0001$ for both). Of 3628 infants and toddlers for whom data were available, $13 \%$ had a weight-for-length $\geq 95$ th percentile, indicating overweight. Of these, 26.9\% were non-Hispanic whites, 39.3\% were Mexican-Americans and $19.5 \%$ were non-Hispanic blacks. Mexican-American infants and toddlers were more likely to be classified as overweight compared with non-Hispanic white and black infants and toddlers $(P=0 \cdot 002$; Table 2$)$.
Seventy-one per cent of participants ( $n$ 2624) ever received breast milk $(74.8 \%$ of non-Hispanic whites, $72.9 \%$ of Mexican-Americans, $55.8 \%$ of non-Hispanic blacks). There were several differences in feeding practices among groups based on race/ethnicity. For age the infant was first fed something other than breast milk, age stopped breast-feeding, age first fed formula and age first fed milk, the feeding practice occurred earlier for both Mexican-American and non-Hispanic black infants compared with non-Hispanic white infants (see Table 3 for mean ages and $P$ values). The age of first feeding of solids was earlier for non-Hispanic white infants compared with Mexican-American infants (5.3 v. 5.7 months; $P=0.02)$.

There were also differences in mean macronutrient intakes stratified by race/ethnicity (Table 4). There were no differences in mean intake of protein, saturated fat or fibre according to race/ethnicity; however, non-Hispanic black and white participants had higher energy intake ( $P<0.001$ and $P<0.01$, respectively) compared with Mexican-Americans. Mexican-American participants had lower carbohydrate intake compared with non-Hispanic black participants $(117$ v. $141 \mathrm{~g} / \mathrm{d} ; P<0.001)$. Total fat intake was also lower among Mexican-Americans compared with non-Hispanic blacks $(39 v .43 \mathrm{~g} / \mathrm{d} ; P<0 \cdot 0001$; Table 4).

Micronutrient intakes also differed by race/ethnicity. Mexican-American infants and toddlers had lower $\mathrm{Na}$ intake compared with non-Hispanic black infants and toddlers $(938 v .1160 \mathrm{mg} / \mathrm{d} ; P<0.05)$. Ca intake did not differ, but non-Hispanic black participants consumed more $\mathrm{K}, \mathrm{Fe}, \mathrm{Zn}$ and folate compared with non-Hispanic white and Mexican-American participants $(P=0.03$, $P<0.0001, P=0.04$ and $P<0.0001$, respectively; Table 4) Differences in feeding practices were also present according to income (Table 5). Most differences by income were between income groups at the very bottom

Table 1 Demographic characteristics of US infants and toddlers aged 0-24 months by race/ethnicity: National Health and Nutrition Examination Survey (NHANES) 2003-2012

\begin{tabular}{|c|c|c|c|c|c|c|c|c|}
\hline & \multicolumn{2}{|c|}{$\begin{array}{l}\text { Non-Hispanic white } \\
\quad(n \text { 1143) }\end{array}$} & \multicolumn{2}{|c|}{$\begin{array}{l}\text { Mexican-American } \\
\quad(n \text { 1225) }\end{array}$} & \multicolumn{2}{|c|}{$\begin{array}{l}\text { Non-Hispanic black } \\
(n \text { 720) }\end{array}$} & \multicolumn{2}{|c|}{$\begin{array}{c}\text { All } \\
\text { (n 3669) }\end{array}$} \\
\hline & $n$ & $\%$ & $n$ & $\%$ & $n$ & $\%$ & $n$ & $\%$ \\
\hline Male & 603 & $52 \cdot 8$ & 623 & $50 \cdot 9$ & 360 & $50 \cdot 0$ & 1881 & 51.3 \\
\hline Female & 540 & $47 \cdot 2$ & 602 & $49 \cdot 1$ & 360 & $50 \cdot 0$ & 1778 & 48.5 \\
\hline Age $0-5.9$ months & 351 & $30 \cdot 7$ & 391 & 31.9 & 196 & $27 \cdot 2$ & 1107 & $30 \cdot 1$ \\
\hline Age $6-11.9$ months & 342 & 29.9 & 366 & 29.9 & 179 & $24 \cdot 9$ & 1063 & 29.0 \\
\hline Age $12-24$ months & 450 & 39.4 & 468 & $38 \cdot 2$ & 345 & $47 \cdot 9$ & 1499 & $40 \cdot 9$ \\
\hline \multicolumn{9}{|l|}{ Annual income } \\
\hline 0-\$US 9999 & 107 & 9.4 & 120 & 9.8 & 158 & 21.9 & 451 & $12 \cdot 3$ \\
\hline \$US $10000-19999$ & 173 & $15 \cdot 1$ & 357 & $29 \cdot 1$ & 160 & $22 \cdot 2$ & 798 & 21.7 \\
\hline \$US 20 000-34 999 & 218 & $19 \cdot 1$ & 313 & $25 \cdot 6$ & 146 & $20 \cdot 3$ & 813 & $22 \cdot 2$ \\
\hline \$US 35 000-44 999 & 75 & $6 \cdot 6$ & 112 & $9 \cdot 1$ & 53 & 7.4 & 284 & $7 \cdot 7$ \\
\hline \$US 45 000-54 999 & 90 & 7.9 & 76 & $6 \cdot 2$ & 51 & $7 \cdot 1$ & 250 & $6 \cdot 8$ \\
\hline \$US 55 000-64 999 & 76 & $6 \cdot 7$ & 40 & 3.3 & 23 & $3 \cdot 2$ & 162 & 4.4 \\
\hline \$US 65 000-74 999 & 58 & $5 \cdot 1$ & 37 & 3.0 & 27 & $3 \cdot 8$ & 143 & 3.9 \\
\hline$\geq \$$ US 75000 & 306 & $26 \cdot 8$ & 99 & $8 \cdot 1$ & 69 & $9 \cdot 6$ & 582 & $15 \cdot 9$ \\
\hline Other & 40 & 3.5 & 71 & $5 \cdot 8$ & 33 & 4.6 & 186 & $5 \cdot 1$ \\
\hline
\end{tabular}


Table 2 Anthropometric measurements of US infants and toddlers aged 0-24 months by race/ethnicity: National Health and Nutrition Examination Survey (NHANES) 2003-2012*, $†$

\begin{tabular}{|c|c|c|c|c|c|c|c|c|}
\hline & \multicolumn{2}{|c|}{ Non-Hispanic white } & \multicolumn{2}{|c|}{ Mexican-American } & \multicolumn{2}{|c|}{ Non-Hispanic black } & \multicolumn{2}{|r|}{ All } \\
\hline & Mean & $95 \% \mathrm{CL}$ & Mean & $95 \% \mathrm{CL}$ & Mean & $95 \% \mathrm{CL}$ & Mean & $95 \% \mathrm{CL}$ \\
\hline $0-2.9$ months & \multicolumn{2}{|r|}{$n 176$} & \multicolumn{2}{|r|}{ n 192} & \multicolumn{2}{|r|}{$n 98$} & \multicolumn{2}{|r|}{$n 554$} \\
\hline Birth weight (kg) & $3 \cdot 10$ & $2 \cdot 98,3.22$ & $3 \cdot 13$ & $3.04,3 \cdot 21$ & 2.96 & $2.85,3.08$ & 3.08 & $3.01,3.14$ \\
\hline Weight $(\mathrm{kg}) \ddagger$ & $5 \cdot 39$ & $5 \cdot 22,5 \cdot 57$ & $5 \cdot 46$ & $5 \cdot 30,5 \cdot 63$ & $5 \cdot 33$ & $5 \cdot 11,5 \cdot 55$ & 5.42 & $5 \cdot 32,5 \cdot 52$ \\
\hline Overweight (\%)§ & \multirow{2}{*}{\multicolumn{2}{|c|}{$\begin{array}{c}6 \cdot 8 \\
n 175\end{array}$}} & \multirow{2}{*}{\multicolumn{2}{|c|}{$\begin{array}{l}14 \cdot 2 \\
n 199\end{array}$}} & \multirow{2}{*}{\multicolumn{2}{|c|}{$\begin{array}{l}9 \cdot 2 \\
n 98\end{array}$}} & \multirow{2}{*}{\multicolumn{2}{|c|}{$\begin{array}{c}11.0 \\
n 549\end{array}$}} \\
\hline 3-5.9 months & & & & & & & & \\
\hline Birth weight (kg) & $3 \cdot 15$ & $3.03,3.26$ & 3.08 & $2.97,3.18$ & 2.85 & $2.67,3.02$ & 3.07 & $2 \cdot 99,3 \cdot 15$ \\
\hline Weight $(\mathrm{kg}) \ddagger$ & $7 \cdot 39$ & $7 \cdot 20,7 \cdot 57$ & $7 \cdot 36$ & $7 \cdot 22,7 \cdot 50$ & $7 \cdot 38$ & $7 \cdot 11,7.65$ & $7 \cdot 37$ & $7 \cdot 24,7 \cdot 50$ \\
\hline Overweight (\%)§ & \multirow{2}{*}{\multicolumn{2}{|c|}{$\begin{array}{c}8 \cdot 0 \\
n 171\end{array}$}} & \multirow{2}{*}{\multicolumn{2}{|c|}{$\begin{array}{c}7.6 \\
n 190\end{array}$}} & \multirow{2}{*}{\multicolumn{2}{|c|}{$\begin{array}{l}13 \cdot 3 \\
n 85\end{array}$}} & \multirow{2}{*}{\multicolumn{2}{|c|}{$\begin{array}{c}8.9 \\
n 533\end{array}$}} \\
\hline $6-8.9$ months & & & & & & & & \\
\hline Birth weight (kg) & $3 \cdot 18$ & $3.06,3.29$ & $3 \cdot 11$ & $2.99,3.22$ & 2.92 & $2.78,3.05$ & $3 \cdot 10$ & $3.03,3.17$ \\
\hline Weight $(\mathrm{kg}) \ddagger$ & 8.54 & $8.38,8.70$ & 8.62 & $8 \cdot 44,8 \cdot 80$ & 8.83 & $8.57,9 \cdot 10$ & 8.55 & $8.45,8.66$ \\
\hline Overweight (\%)§ & \multicolumn{2}{|r|}{$\begin{array}{l}14 \cdot 1 \\
n \cdot 171\end{array}$} & \multirow{2}{*}{\multicolumn{2}{|c|}{$\begin{array}{c}14.7 \\
n 172\end{array}$}} & \multirow{2}{*}{\multicolumn{2}{|c|}{$\begin{array}{l}12 \cdot 9 \\
n 94\end{array}$}} & \multirow{2}{*}{\multicolumn{2}{|c|}{$\begin{array}{c}12 \cdot 8 \\
n 522\end{array}$}} \\
\hline 9-11.9 months & \multicolumn{2}{|r|}{ n 171} & & & & & & \\
\hline Birth weight (kg) & $3 \cdot 15$ & $3.06,3.25$ & 3.04 & $2 \cdot 91,3.17$ & $2 \cdot 82$ & $2 \cdot 68,2.96$ & 3.09 & $3.01,3 \cdot 16$ \\
\hline Weight $(\mathrm{kg}) \ddagger$ & $9 \cdot 62$ & $9.40,9.84$ & 9.62 & $9.38,9.87$ & 9.64 & $9.38,9.90$ & 9.59 & $9.44,9.74$ \\
\hline Overweight (\%)§ & \multicolumn{2}{|r|}{$\begin{array}{l}15.4 \\
n 211\end{array}$} & \multirow{2}{*}{\multicolumn{2}{|c|}{$\begin{array}{c}18 \cdot 6 \\
n 231\end{array}$}} & \multirow{2}{*}{\multicolumn{2}{|c|}{$\begin{array}{c}18.1 \\
n 157\end{array}$}} & \multicolumn{2}{|r|}{$16 \cdot 7$} \\
\hline $12-17.9$ months & \multicolumn{2}{|r|}{$n 211$} & & & & & & n 699 \\
\hline Birth weight (kg) & $3 \cdot 13$ & $3.04,3 \cdot 21$ & $3 \cdot 10$ & $3.00,3 \cdot 19$ & 3.01 & $2 \cdot 89,3 \cdot 13$ & 3.09 & $3.03,3.15$ \\
\hline Weight $(\mathrm{kg}) \ddagger$ & $10 \cdot 66$ & $10.43,10 \cdot 89$ & $10 \cdot 74$ & $10.54,10.94$ & $10 \cdot 84$ & $10 \cdot 57,11 \cdot 10$ & $10 \cdot 70$ & $10 \cdot 56,10 \cdot 84$ \\
\hline Overweight (\%)§ & & $14 \cdot 0$ & & $20 \cdot 2$ & & $12 \cdot 8$ & & $15 \cdot 5$ \\
\hline 18-24 months & & $n 239$ & & $n 232$ & & $n 186$ & & $n 771$ \\
\hline Birth weight $(\mathrm{kg})$ & $3 \cdot 22$ & $3 \cdot 14,3 \cdot 30$ & $3 \cdot 11$ & $3.04,3.19$ & 2.96 & $2.89,3.03$ & $3 \cdot 14$ & $3 \cdot 10,3 \cdot 20$ \\
\hline Weight $(\mathrm{kg}) \ddagger$ & 12.07 & $11 \cdot 82,12 \cdot 31$ & 12.42 & $12 \cdot 17,12 \cdot 67$ & $12 \cdot 19$ & $11 \cdot 77,12 \cdot 61$ & $12 \cdot 15$ & $11.99,12.31$ \\
\hline Overweight (\%)§ & & 9.9 & & $17 \cdot 0$ & & $12 \cdot 4$ & & $13 \cdot 4$ \\
\hline All ages & & $n 1143$ & & $n 1244$ & & $n 718$ & & n 3628 \\
\hline Birth weight (kg) & $3 \cdot 16$ & $3 \cdot 11,3 \cdot 21$ & $3 \cdot 10$ & $3.06,3.14$ & 2.92 & $2 \cdot 88,2.99$ & $3 \cdot 10$ & $3.07,3 \cdot 13$ \\
\hline Overweight (\%)§ & & 11.4 & & $15 \cdot 4$ & & $13 \cdot 1$ & & $13 \cdot 1$ \\
\hline
\end{tabular}

${ }^{*}$ Data are presented as survey-weighted means and $95 \%$ confidence levels (CL), unless indicated otherwise.

†Total $n$ 3628. Missing data for forty-one participants, demographics similar to Table 1.

$\ddagger$ Measurement performed when NHANES survey was administered.

$\S$ Percentage of group by race/ethnicity plotting $\geq 95$ th percentile weight-for-length on WHO birth to 24 months growth charts.

and very top of the spectrum. Cessation of breast-feeding occurred earlier in the lower income groups $(<\$$ US 35000 ) compared with the \$US 45000-54999 and $\geq \$$ US 75000 groups ( $4.1 v .5 .5$ and 5.8 months; $P=0.007$ and $P=0.0005$, respectively). The age at which infants were first fed formula was earlier for households with income of <\$US 35000 compared with the \$US 55000 64999 or $\geq \$$ US 75000 groups (1.3 v. 2.6 and 2.5 months; $P=0.007$ and $P<0.0001$, respectively). The age at which infants stopped receiving formula was also earlier for households with income <US $\$ 35000$ compared with those with incomes of \$US 65000-74999 or $\geq \$$ US 75000 annually ( $P=0.0001$ and $P=0.03$, respectively).

Finally, there were differences in mean nutrient intakes according to income (Table 6). Clear differences according to upper and lower income groups were not universally present; however, the highest income group ( $\geq$ \$US 75000 annual income) had decreased energy intake compared with the lowest income groups ( < \$US 35000 annual income; $P$ for trend $=0.002$ ). In addition, the highest income group had decreased saturated fat intake compared with the lowest income groups ( $P$ for trend $=0.003$ ). Along with higher energy intake, the trend in lower income groups was for higher intake of several micronutrients: $\mathrm{Na}, \mathrm{Fe}, \mathrm{Zn}$, vitamin $\mathrm{E}$, vitamin $\mathrm{A}$, vitamin $\mathrm{C}$ and vitamin $\mathrm{B}_{12}$ ( $P$ for trend $=0.01,0 \cdot 001,<0.0001,<0 \cdot 0001$, $0.002, \quad 0.0001$ and 0.0002 , respectively). Significant interactions $(P<0.05)$ between race/ethnicity and income were found for feeding practices and for intakes of most nutrients with the exceptions of protein, total fat, fibre, $\mathrm{K}, \mathrm{Ca}$ and vitamin $\mathrm{B}_{12}$ (Tables 5 and 6). Of these nutrients, intakes of only total fat and $\mathrm{K}$ were different by race/ ethnicity, with lower intake of both among MexicanAmericans and non-Hispanic whites.

\section{Discussion}

The Feeding Infants and Toddlers Study (FITS 2002 and $2008)^{(28,29,33)}$ and the Infant Feeding Practices Study II (IFPS II) ${ }^{(30-32)}$ have both provided important insights into feeding practices for children from birth to 24 months. However, FITS used a commercial list of infants and toddlers, which under-represented children from groups of lower socio-economic status and certain race/ethnicities $^{(28,29,33)}$. IFPS II was also limited by lower participation of minority groups and higher participation of infants of higher socio-economic status. NHANES includes a nationally representative sample, providing important information about how historically under-represented 
groups and low-income groups differ in overweight, feeding practices and mean nutrient intake levels.

The present study identified a few differences in feeding practices compared with FITS and IFPS. A lower proportion of women in the NHANES sample (which is lower education level, younger age, lower socio-economic status, and more diverse) initiated breast-feeding compared with the IFPS II and FITS samples (71.5 v. 83 and $80 \%$, respectively). The median age of initiation of solids or complementary foods in NHANES was higher compared with IFPS II and FITS ( $\sim 5$ months compared with 4 months for both IFPS and FITS ${ }^{(28-31)}$.

When comparing feeding practices in NHANES with those recommended by the American Academy of Pediatrics and Academy of Nutrition and Dietetics ${ }^{(39,40)}$, the mean age of introduction of something other than breast-feeding or water was about 3-4 months earlier than the recommended time for exclusive breast-feeding of 6 months. The total mean duration of breast-feeding (5 months) was about 1 month less than the recommended time for exclusive breast-feeding ( 6 months) and more than 6 months less than the recommended time for beginning of weaning from the breast $(12 \text { months })^{(39,40)}$. The present study reaffirms that infant feeding practices fall short of what is recommended. Breast-feeding initiation rates remain low (71\%) and many infants receive infant formula at an early age.

Rates of overweight in the present study are higher than those reported in other investigations using similar data ${ }^{(13)}$ (13 v. 8\%), in part because the 95th percentile on the WHO chart was chosen as the comparative standard rather than the 95th percentile on the Centers for Disease Control and Prevention chart. In addition, disparities by race/ethnicity and income existed, with lower birth weight among nonHispanic blacks and Mexican-Americans. However, it is unusual to note that despite similar feeding practices among both Mexican-American and non-Hispanic black parents, only Mexican-American infants and toddlers had higher rates of early overweight. Among non-white infants and toddlers, rates of breast-feeding were lower, breast-feeding cessation occurred earlier, and introduction of water, formula and milk all occurred earlier compared with non-Hispanic whites. Differences in mean nutrient intakes according to both race/ethnicity and income also existed. Mexican-Americans had the lowest reported energy, carbohydrate and fat intakes. Non-Hispanic blacks had the highest reported energy, carbohydrate and fat intakes. In general, reported energy intake was higher in lower income groups, with protein intake being similar among groups but with higher intakes of total fat and total carbohydrate in lower income groups. There was no difference in fibre intake among groups; however, there were higher intakes of many nutrients, including vitamin C, Fe and energy, in the lowest income groups and non-Hispanic black infants. This may be indicative of higher intakes of cheaper, processed but fortified foods and juices ${ }^{(41)}$. 
Why reported intakes were lowest in Mexican-Americans, the group with the highest overweight rate, is unclear. It is possible that Mexican-American parents under-report intake consistently, but this diverges from the higher reported intake levels in lower income groups, who are also at increased risk for overweight.

Any conclusions related to nutrient intakes are limited by the absence of using statistical methods to estimate usual intakes of nutrients. However, since this deficit was present across all groups, and the intention was to simply compare groups, not to compare intakes with desirable standards, this approach was unlikely to invalidate the comparison. In addition, one recent analysis indicated that in a group of Mexican infants, toddlers and pre-school children, there was no difference in estimated intakes determined using one-day analyses $v$. usual intake methods for most nutrients except for fat and $\mathrm{Fe}^{(42)}$. Trends in differences according to income were clear but not consistent across all income levels. It should be noted that it is difficult to disentangle race/ethnicity from income since Mexican-American and black families are more likely to suffer low income compared with white families. Thus, the effect of income appears to be greater in non-Hispanic whites.

It is interesting that the group with the highest rates of early overweight (Mexican-Americans) had similar rates of breast-feeding initiation and duration, later introduction of solids, and lower energy and carbohydrate intakes compared with non-Hispanic blacks, who did not have rates of overweight disproportionate to their sample size. However, there is a significant, emerging body of literature that indicates early feeding practices may be less influential than previously thought. For example, Daniels et al. ${ }^{(43)}$ reviewed twenty papers related to feeding practices and later obesity and found that there was only slight evidence for introduction of solids at earlier than 4 months of age being associated with obesity. They identified methodological problems with the studies that have been done in this area. A recent paper which found increased risk for obesity with both early and late introduction of solids had only nine participants in the 'early' group and just ten in the 'late' group ${ }^{(44)}$. In a much more nuanced study of early feeding patterns by Rose et al., only early feeding of sugary and fatty foods such as cookies and fries was associated with early obesity ${ }^{(45)}$. Likewise, Barrera et al. ${ }^{(46)}$ and Leary et $a l .{ }^{(47)}$ both found an increased risk of obesity for early feeding disappeared after adjusting for covariates. Finally, Kerr et al. ${ }^{(48)}$ also found that baseline information such as child and maternal BMI, maternal age and education, and child health were the strongest predictors of onset and resolution of obesity in the school years with perinatal, breast-feeding and lifestyle exposures not being predictive. It is possible that early obesity in MexicanAmerican infants and toddlers, which is correlated to higher later obesity ${ }^{(16-22)}$, relates more to genetic or parental factors or simply that Mexican-American parents are more prone to under-reporting offering high-energy 
Table 5 Infant feeding practices of US infants and toddlers aged 0-24 months by annual income: National Health and Nutrition Examination Survey (NHANES) 2003-2012*

\begin{tabular}{|c|c|c|c|c|c|c|c|c|c|c|c|c|c|}
\hline & \multicolumn{3}{|c|}{ 0-\$US 9999} & \multicolumn{3}{|c|}{ \$US 10 000-19999 } & \multicolumn{3}{|c|}{ \$US 20 000-34 999} & \multicolumn{3}{|c|}{ \$US 35 000-44 999} & \\
\hline & $n \dagger$ & Mean & $95 \% \mathrm{CL}$ & $n \dagger$ & Mean & $95 \% \mathrm{CL}$ & $n \dagger$ & Mean & $95 \% \mathrm{CL}$ & $n \dagger$ & Mean & $95 \% \mathrm{CL}$ & \\
\hline Age first fed something other than breast milk or water & 161 & 1.9 & $1.5,2 \cdot 4$ & 326 & $2 \cdot 4$ & $2 \cdot 1,2 \cdot 7$ & 338 & $2 \cdot 6$ & $2 \cdot 2,3 \cdot 1$ & 73 & $2 \cdot 8$ & $2 \cdot 1,3 \cdot 0$ & \\
\hline Age stopped breast-feeding & 181 & $3 \cdot 2$ & $2 \cdot 6,3 \cdot 8$ & 369 & 3.8 & $3 \cdot 3,4 \cdot 3$ & 395 & 4.8 & $4.1,5.4$ & 78 & 4.7 & $3 \cdot 6,6 \cdot 0$ & \\
\hline Age first fed formula & 407 & 0.9 & $0.7,1 \cdot 1$ & 714 & $1 \cdot 3$ & $1 \cdot 1,1.5$ & 704 & 1.5 & $1.1,1.9$ & 115 & 1.8 & $0.8,1.5$ & \\
\hline Age stopped getting formula & 182 & $10 \cdot 8$ & $10 \cdot 4,11 \cdot 2$ & 305 & 11.4 & $11 \cdot 1,11 \cdot 7$ & 281 & $11 \cdot 0$ & $10 \cdot 4,11.5$ & 50 & 11.7 & $10 \cdot 9,11 \cdot 8$ & \\
\hline Age first fed milk & 207 & $11 \cdot 1$ & $10 \cdot 8,11 \cdot 3$ & 353 & $11 \cdot 1$ & $10.9,11.4$ & 330 & 11.4 & $11 \cdot 0,11.8$ & 62 & 11.4 & $11 \cdot 1,12 \cdot 0$ & \\
\hline \multirow[t]{3}{*}{ Age first fed solids } & 248 & 5.4 & $4 \cdot 8,5 \cdot 9$ & 423 & $5 \cdot 5$ & $5 \cdot 3,5 \cdot 8$ & 390 & $5 \cdot 4$ & $5 \cdot 0,5 \cdot 8$ & 71 & $5 \cdot 8$ & $5 \cdot 2,6 \cdot 2$ & \\
\hline & \multicolumn{3}{|c|}{ \$US 45 000-54 999} & \multicolumn{3}{|c|}{ \$US 55 000-64 999} & \multicolumn{3}{|c|}{ \$US 65 000-74 999} & \multicolumn{3}{|c|}{$\geq \$$ US 75000} & \\
\hline & $n \dagger$ & Mean & $95 \% \mathrm{CL}$ & $n \dagger$ & Mean & $95 \% \mathrm{CL}$ & $n \dagger$ & Mean & $95 \% \mathrm{CL}$ & $n \dagger$ & Mean & $95 \% \mathrm{CL}$ & $P$ value for trend \\
\hline er than breast milk or water & 122 & $2 \cdot 8$ & $2 \cdot 3,3 \cdot 4$ & 82 & $2 \cdot 7$ & $1.9,3.5$ & 73 & $2 \cdot 8$ & $2 \cdot 0,3 \cdot 6$ & 244 & $3 \cdot 3$ & $2.7,3.9$ & 0.0001 \\
\hline Age stopped breast-feeding & 144 & 5.5 & $4.5,6.4$ & 92 & 4.6 & $3.5,5.7$ & 78 & 4.7 & $3.5,5.8$ & 319 & $5 \cdot 8$ & $5 \cdot 0,6 \cdot 6$ & $<0.0001$ \\
\hline Age first fed formula & 204 & 1.7 & $1 \cdot 2,2 \cdot 2$ & 134 & $2 \cdot 6$ & $1 \cdot 7,3.4$ & 115 & 1.8 & $1 \cdot 1,2 \cdot 6$ & 457 & 2.5 & $2 \cdot 1,3 \cdot 0$ & $<0.0001$ \\
\hline Age stopped getting formula & 94 & 11.2 & $10.5,11.9$ & 57 & $11 \cdot 7$ & $10 \cdot 7,12 \cdot 7$ & 50 & 11.7 & $11.5,11.9$ & 191 & 11.7 & $11 \cdot 3,12 \cdot 0$ & 0.001 \\
\hline Age first fed milk & 119 & 11.4 & $11 \cdot 2,11 \cdot 7$ & 70 & 11.5 & $10 \cdot 7,12 \cdot 4$ & 62 & 11.4 & $11 \cdot 1,11 \cdot 8$ & 247 & 11.6 & $11.4,11.8$ & 0.01 \\
\hline Age first fed solids & 134 & 5.4 & $4 \cdot 7,6 \cdot 1$ & 83 & $5 \cdot 3$ & $4 \cdot 8,5 \cdot 8$ & 71 & $5 \cdot 8$ & $5 \cdot 0,6 \cdot 5$ & 254 & $5 \cdot 4$ & $5 \cdot 1,5 \cdot 8$ & 0.77 \\
\hline
\end{tabular}

Data are presented as survey-weighted means and $95 \%$ confidence limits $(\mathrm{CL})$ in months.

†Number of participants within each category responding to each question. 
foods, a common occurrence in parents of overweight and obese children.

The present study of NHANES data is unique because it compares feeding practices and nutrient intakes of infants and toddlers by race/ethnicity and income. It is not surprising that we found differences in feeding practices according to race/ethnicity given well-known cultural differences in eating patterns and health disparities ${ }^{(49,50)}$. However, the present study had several limitations in addition to those already mentioned. The racial groups 'other Hispanic' and 'other race/ethnicity' were too small to allow for comparisons. In addition, racial/ethnic categories are largely cultural rather than biological designations, and not all individuals who identify with a particular culture may have the feeding practices or food intake considered common to that culture. As stated before, differences in intakes and feeding practices according to race/ethnicity and income are correlated and impossible to fully disentangle. Finally, the questions asked in the NHANES questionnaire are broad and do not allow for insight into the reasoning behind parental feeding decisions.

\section{Conclusion}

The present study showed consistent disparities in feeding practices among lower income parents and parents of Mexican-American infants and toddlers compared with higher income and white, non-Hispanic parents. In addition, nutrient intake disparities were also identified. These disparities provide support for the Special Supplemental Nutrition Program for Women, Infants, and Children, which provides nutrition education in addition to supplemental foods because although low-income children and children of certain races/ethnicities often had higher nutrient intakes, they also had less optimal feeding practices. In addition, the study supports the notion that low-income parents and parents of colour should be the focus of interventions to improve early feeding practices and actual food intake to potentially mediate early obesity.

To reduce early obesity, future research should evaluate patterns of food intake, not only nutrients, to gain better insight into how to best educate parents to improve the diet of young children. Longitudinal research to follow offspring of parents who get more intensive or targeted anticipatory guidance regarding infant feeding would also be desirable to determine if intensive efforts result in improved outcomes in adolescent and adult obesity. In addition, more qualitative research is needed with parents, especially lower-income parents and parents of colour, to determine what factors most affect feeding decisions and how best to intervene with parents to improve feeding practices and reduce infant overweight.

\section{Acknowledgements}

Financial support: This work was supported by the National Center for Advancing Translational Sciences of 
the National Institutes of Health (NIH; award number UL1TR001105). The content is solely the responsibility of the authors and does not necessarily represent the official views of the NIH. NIH had no role in the design, analysis or writing of this article. Conflict of interest: The authors have no conflicts of interest relevant to this article to disclose. Authorship: K.E.D. developed the concept and designed the study, oversaw the study, drafted the initial manuscript, and approved the final manuscript as submitted. X.L. conducted the initial data extraction and analysis, drafted the statistical section of the initial manuscript, and approved the final manuscript as submitted. B.A.-H. advised X.L. on the statistical methods, revised the statistical section of subsequent drafts, and approved the final manuscript as submitted. L.S. provided advice regarding the study design and multiple phases of the research, provided editing and feedback regarding the layout and content of the manuscript, and approved the final manuscript as submitted. Ethics of human subject participation: This study was conducted according to the guidelines laid down in the Declaration of Helsinki. All procedures in the NHANES protocol involving human subjects/patients were approved by the National Center for Health Statistics' Research Ethics Review Board and all parents provided informed consent.

\section{Supplementary material}

To view supplementary material for this article, please visit https://doi.org/10.1017/S1368980017003184

\section{References}

1. Pulgaron ER (2013) Childhood obesity: a review of increased risk for physical and psychological conditions. Clin Ther 35, A18-A32.

2. Levin A, Morad Y, Grotto I et al. (2010) Weight disorders and associated morbidity among young adults in Israel: 1990-2003. Pediatr Int 52, 347-352.

3. Kelly AS, Barlow SE, Rao G et al. (2013) Severe obesity in children and adolescents: identification of associated health risks and treatment approaches. Circulation 128, $1689-1712$.

4. Damaso AR, do Prado WL, de Piano A et al. (2008) Relationship between nonalcoholic fatty liver disease prevalence and visceral fat in obese adolescents. Dig Liver Dis 40, 132-139.

5. Eminoglu TF, Camurdan OM, Oktar SO et al. (2008) Factors related to non-alcohol fatty liver disease in obese children. Turk J Gastroenterol 19, 85-91.

6. Suano de Souza JL, Silverio Amancio OM, Saccardo Sarni RO et al. (2008) Non-alcoholic fatty liver disease in overweight children and its relationship with retinol serum levels. Int J Vitam Nutr Res 78, 27-32.

7. Anderson SE, Cohen P, Naumova EN et al. (2006) Association of depression and anxiety disorders with weight change in a prospective community-based study of children followed into adulthood. Arch Pediatr Adolesc Med 160, 285-291.
8. Bell LM, Byrne S, Thompson A et al. (2007) Increasing BMI z-score is continuously associated with complications of overweight in children, even in the healthy weight range. $J$ Clin Endocrinol Metab 92, 517-522.

9. Bell LM, Curran JA, Byrne S et al. (2011) High incidence of obesity co-morbidities in young children: a crosssectional study. I Paediatr Child Health 47, 911-917.

10. Hillman JB, Dorn LD \& Bin H (2010) Association of anxiety and depressive symptoms and adiposity among adolescent females, using dual X-ray absorptiometry. Clin Pediatr (Phila) 49, 671-677.

11. Merinkangas AK, Mendola P, Pastor PN et al. (2012) The association between major depressive disorder and obesity in US adolescents: results from the 2001-2004 National Health and Nutrition Examination Survey. J Behav Med 35, 149-154.

12. US Department of Health and Human Services, Office of Disease Prevention and Health Promotion (2014) Healthy People 2020. Nutrition and weight status. https://www. healthypeople.gov/2020/topics-objectives/topic/nutrition-andweight-status/objectives (accessed February 2017).

13. Ogden CL, Carroll MD, Kit BK et al. (2014) Prevalence of childhood and adult obesity in the United States: 2011-2012. JAMA 311, 806-814.

14. Ogden CL, Carroll MD, Kit BK et al. (2012) Prevalence of obesity and trends in body mass index among US children and adolescents: 1999-2010. JAMA 307, 483-490.

15. Barlow SE (2007) Expert committee recommendations regarding the prevention, assessment, and treatment of child and adolescent overweight and obesity: a summary report. Pediatrics 120, Suppl. 4, S164-S192.

16. Monteiro PO, Victora CG, Barros FC et al. (2003) Birth size, early childhood growth, and adolescent obesity in a Brazilian birth cohort. Int J Obes Relat Metab Disord 27, 1274-1282.

17. Monteiro PO \& Victora CG (2005) Rapid growth in infancy and childhood and obesity in later life, a systematic review. Obes Rev 6, 143-154.

18. Stettler N, Kumanyika SK, Katz SH et al. (2003) Rapid weight gain during infancy and obesity in young adulthood: a cohort of African Americans. Am J Clin Nutr 77, 1374-1378.

19. Reilly JJ, Armstrong J, Dorosty AR et al. (2005) Early life risk factors for obesity in childhood: cohort study. BMJ 330, 1357.

20. Druet C, Stettler N, Sharp S et al. (2012) Prediction of childhood obesity by infancy weight gain: an individual level meta-analysis. Paediatr Perinat Epidemiol 26, 19-26.

21. Young BE, Johnson SL \& Krebs NF (2012) Biological determinants linking infant weight gain and child obesity: current knowledge and future directions. Adv Nutr 3, 675-686.

22. Sacco MR, de Castro NP, Euclydes VLV et al. (2013) Birth weight, rapid weight gain in infancy and markers of overweight and obesity in childhood. Eur J Clin Nutr 67, $1147-1153$.

23. Harrington JW, Nguyen VQ, Paulson JF et al. (2010) Identifying the 'tipping point' age for overweight pediatric patients. Clin Pediatr (Phila) 49, 538-643.

24. Taveras EM, Rifas-Shiman SL, Sherry B et al. (2011) Crossing growth percentiles in infancy and risk of obesity in childhood. Arch Pediatr Adolesc Med 165, 993-998.

25. Paul IM, Bartok SJ, Downs DS et al. (2009) Opportunities for the primary prevention of obesity during infancy. Adv Pediatr 56, 107-133.

26. Daniels LA, Mallan KM, Nicholson JM et al. (2013) Outcomes of an early feeding practices intervention to prevent childhood obesity. Pediatrics 132, e109-e118.

27. Davis JN, Koleilat M, Shearrer GE et al. (2014) Association of infant feeding and dietary infant on obesity prevalence in low-income toddlers. Obesity (Silver Spring) 22, 1103-1111. 
28. Dwyer JT, Butte NF, Deming DM et al. (2010) Feeding Infants and Toddlers Study 2008: progress, continuing concerns, and implications. J Am Diet Assoc 110, 12 Suppl., S61-S67.

29. Saavedra JM, Deming D, Dattilo A et al. (2013) Lessons from the Feeding Infants and Toddlers Study in North America: what children eat and implications for obesity prevention. Ann Nutr Metab 62, 27-36.

30. Fein SB, Labiner-Wolfe J, Shealy KR et al. (2008) Infant Feeding Practices Study II: study methods. Pediatrics 122, Suppl. 2, S23-S35.

31. Grummer-Strawn LM, Scanlon KS et al. (2008) Infant feeding and feeding transitions during the first year of life. Pediatrics 122, Suppl. 2, S36-S42.

32. Devaney B, Kalb L, Briefel R et al. (2004) Feeding Infants and Toddlers Study: Overview of the study design. J Am Diet Assoc 104, 1 Suppl. 1, S8-S13.

33. Briefel R (2010) New findings from the Feeding Infants and Toddlers Study: data to inform action. J Am Diet Assoc 110, 12 Suppl., S5-S7.

34. Ahluwalia N, Herrick K, Paulose-Ram R et al. (2014) Data needs for B-24 and beyond: NHANES data relevant for nutrition surveillance of infants and young children. Am J Clin Nutr 99, issue 3, 747S-754S.

35. Centers for Disease Ccontrol and Prevention, National Center for Health Statistics (2011) National Health and Nutrition Examination Survey. http://www.cdc.gov/nhanes/ nhanes_questionnaires.htm (accessed February 2017).

36. Centers for Disease Control and Prevention, National Center for Health Statistics (2010) CDC Clinical Growth Charts. http://www.cdc.gov/growthcharts/who_charts.htm (accessed February 2017).

37. Butte NF, Fox MK, Briefel RR et al. (2010) Nutrient intakes of US infants, toddlers, and preschoolers meet or exceed dietary reference intakes. J Am Diet Assoc 110, 12 Suppl., S27-S37.

38. Briefel RR, Kalb LM, Condon E et al. (2010) The Feeding Infants and Toddlers Study 2008: study design and methods. J Am Diet Assoc 10, 12 Suppl., S16-S26.
39. Butte N, Cobb K, Dwyer J et al. (2004) The Start Healthy Feeding Guidelines for infants and toddlers. J Am Diet Assoc 104, 442-454.

40. American Academy of Pediatrics (2012) Policy Statement: breastfeeding and the use of human milk. Pediatrics 129, e827-e841.

41. Drewnowski A \& Rehn CD (2015) Socioeconomic gradient in consumption of whole fruit and 100\% fruit juice among US children and adults. Nutr J 14, 3 .

42. Piernas C, Miles DR, Deming DM et al. (2016) Estimating usual intakes mainly affects the micronutrient distribution among infants, toddlers, and pre-schoolers from the 2012 Mexican National Health and Nutrition Survey. Public Health Nutr 19, 1017-1026.

43. Daniels L, Mallan KM, Fildes A et al. (2015) The timing of solid introduction in an 'obesogenic environment': a narrative review of the evidence and methodological issues. Aust N Z J Public Health 29, 366-373.

44. Sun C, Foskey RJ, Allen KJ et al. (2016) The impact of timing of introduction of solids on infant body mass index. J Pediatr 179, 104-110.

45. Rose CM, Savage JS \& Birch LL (2016) Patterns of early dietary exposures have implications for maternal and child weight outcomes. Obesity (Silver Spring) 24, 430-438.

46. Barrera CM, Perrine CG, Li R et al. (2016) Age at introduction to solid foods and child obesity at 6 years. Child Obes 12, 188-192.

47. Leary SD, Lawlor DA, Davey Smith G et al. (2015) Behavioural early-life exposures and body composition at age 15 years. Nutr Diabetes 5, e150.

48. Kerr JA, Long C, Clifford SA et al. (2017) Early-life exposures predicting onset and resolution of childhood overweight or obesity. Arch Dis Child 102, 915-922.

49. Centers for Disease Control and Prevention (2013) CDC Health Disparities and Inequalities Report - United States, 2013. https://www.cdc.gov/minorityhealth/chdireport.html (accessed February 2017).

50. Rhodes P, Clemens J \& Moshfegh A (2015) Nutrient intakes and eating patterns of US adults by race/ethnicity. FASEB J 29, 272-275. 